\title{
Study of the Impact of Brain Vascular Accidents on Memorization in Man
}

QR CODE

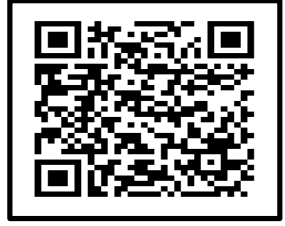

\section{BAKOU NIANGORAN FRANÇOIS*1, ATAYI EUGENE², BA ABDOULAYE³}

BACKGROUND: The search for disruption of memory in patients with stroke has been performed, in order to better understand the behavior of these patients and optimize their neuropsychological accompaniment.

AIM: To evaluate memory disturbances following stroke in patients; in order to better understand the attitudes of these patients. MATERIALS AND METHOD: Fifty-five (55) patients with stroke participated in a spatial memory test. This test consists in studying the arrangement, the designation and the evocation of images during learning a spatial arrangement.

RESULTS: Of the 55 patients, $54.54 \%$ of patients passed the test but with later learning. And $45.45 \%$ failed at different events, they present real memory problems.

CONCLUSION: Our study, confirms that stroke patients face difficulties which often include cognitive impairments, such as memory deficits. Our results indicate that these memory disorders manifest themselves to varying degrees. Indeed, the working memory disorders would be more marked in group II patients than in group I patients or they can be considered transient.

KEYWORDS: Working Memory, Stroke, Learning

\section{INTRODUCTION}

Memory can be defined as the function that enables an organism to acquire, then retain, and evoke information or behavior related to a sensory experience. ${ }^{1}$ This definition covers both forms of memory and elementary elements such as habituation and awareness, forms and complexes and developed as working memory. ${ }^{2}$ This fundamental function is particularly vulnerable in the case of a stroke. Indeed, stroke is the second most common cause of cognitive impairment and dementia and can significantly affect attention, memory, ability to plan, and other executive functions. Strokes are usually classified into two broad categories: ischemic stroke and hemorrhagic stroke.

The first type of stroke, or cerebral infarction, is due to the obstruction of a blood vessel while the second, or cerebral hemorrhage, causes bleeding in the brain. The stroke is caused by a decrease or even a sudden stop of the blood flow in the branches of the vascular network in connection with the vessel undergoing a rupture of its wall or a blockage by a clot. Thus, the nerve cells fed by these branches are suddenly deprived of oxygen and sugars, causing in a few minutes their deterioration or death. In the hemorrhagic case, the decrease is mainly due also to a compression of the nerve cells by the hematoma resulting from the bleeding. As a result, axons of neurons can be sectioned by mass displacement of nerve tissue. In Côte d'Ivoire, where stroke is a real public health problem, few studies have documented memory problems associated with stroke. The objective of this study is to evaluate memory disturbances following stroke in patients; in order to better understand the attitudes of these patients in order to optimize their neuropsychological accompaniment.

\section{MATERIAL AND METHOD}

Study population: The study described here totalled 75 participants of both sexes. The age of the subjects varies between 30 years and 61 years with an average 45.5 years. They are distributed as follows:

- 20 control subjects with no history of neurological, psychiatric and stroke disorders. They were chosen from the general population;

- 55 patients with stroke were recruited from the Department of Neurology of C.H.U of Cocody-Abidjan (Ivory Coast). Patients had focal brain damage due to 
stroke.

Technical material: To perform the spatial memory test, we had a square frame $(400 \mathrm{~mm} \times 400 \mathrm{~mm})$ of dimension where are arranged the 9 images of familiar objects.

Methods: The spatial memory test Fouillot et al., $(1993)^{3}$ used corresponds to the arrangement, the designation and the evocation of images during learning tests of a spatial arrangement. The subject must learn the spatial arrangement of nine images of familiar objects on the nine equal squares of a square frame placed in front of him. The objects represented are: a bicycle, a tam-tam, a mango, a key, a mask, a canary, a machete, a boubou, and a pig. The disposition of each image is shown to a subject successively for 5 seconds per image. The instruction to remember the place of the image in the frame is clearly given. The delay between the presentation of the images and the start of the recall is three minutes during which the subject performs a simple interfering task to perform (mental calculation or conversation). For the next test (the arrangement), the subject must place each image in its box. For the designation test, the subject is obliged to recognize the box of the object presented by the experimenter. Finally, in the evocation test, the subject must give the name of the object corresponding to the box designated by the experimenter. For each test, the learning criterion of the spatial arrangement is fixed at three successive tests without errors. In case of failure, the test is stopped after ten attempts and considered as a learning failure. After a full description of the subject study, written consent was obtained.

Statistical analysis: For this test, the sample is a series of tests up to a maximum of ten when the memorization is late or has not been established. The character studied is the number of errors per test.

The storage of the spatial position on nine images of usual objects, the maximum number of errors may be nine. For the statistical analysis of the results, the chisquare test of the software statistica version 6.0 was used. Significance was asked for $\mathrm{P}<0.05$. The determination of the percentage of errors is determined as follows:

Number of errors for the trial considered $\mathbf{x} 100$

Maximum number of errors

Number of errors for the trial considered $\mathbf{x} \mathbf{1 0 0}$
Moreover, for each series of experiments, two groups of subjects are to be compared: control subjects, subjects with stroke. It involves analyzing the overall behavior of each group through their performances and comparing these results. Thus, it is necessary to verify the significance of the probable differences observed between the averages of the errors obtained in each group, i.e. whether for each test the difference in performance between two given groups is significant or not. To do this, a univariate analysis of variance (ANOVA), using the Statistica 6.o software, made these comparisons possible. Thus, if "p" is less than or equal to 0.05 , then the difference between the compared variables is significant. On the other hand, if "p" is greater than 0.05, then the difference between the two variables compared is not significant.

\section{RESULTS}

The analysis of the performances performed in the different tests makes it possible to distinguish two groups of patients:

- Group I $(\mathrm{n}=30) 54.54 \%$ composed of patients having inferior performance to control subjects with later learning;

- Group II $(n=25) 45.45 \%$ of patients who failed the various tests of the spatial memory test. The reminder of the spatial arrangement of the nine images was not possible for patients in group II. Indeed, in the agreement test, the comparison of the performances of the subjects of the groups I and the control subjects, reveals a significant difference because $(F(1,46)=10,04$, $\mathrm{p}=\mathrm{o}, 0027)$. Comparison of the performance of control and group II patients shows a significant difference ( $\mathrm{F}$ $(1.46)=8.14, \mathrm{p}=0.0065)$; finally, there is a significant difference between the performance of Group I and Group II patients $(\mathrm{F}(1.46)=9.14, \mathrm{p}=0.0055)$. (Figure 1 ). In the designation trial, the performance of group I patients was significantly different from the controls because $(F(1.46)=12.76, p=0.0008)$. The performance of patients in group II compared to those in control subjects was also significantly different indeed, (F (1.46) $=4.75, \mathrm{p}=0.0344)$. There was a significant difference in the performance of patients in group II group I ( $\mathrm{F}(1.46)$ $=5.50, \mathrm{p}=0.0344)$. (Figure 2 )

Finally, in the evocation test, the performance analysis of control subjects and group I patients indicated a significant difference because $(\mathrm{F}(1.46)=8.89, \mathrm{p}=$ o.0046). Similarly, the performance of group II and control patients was significantly different $(\mathrm{F}(1.46)=$ 


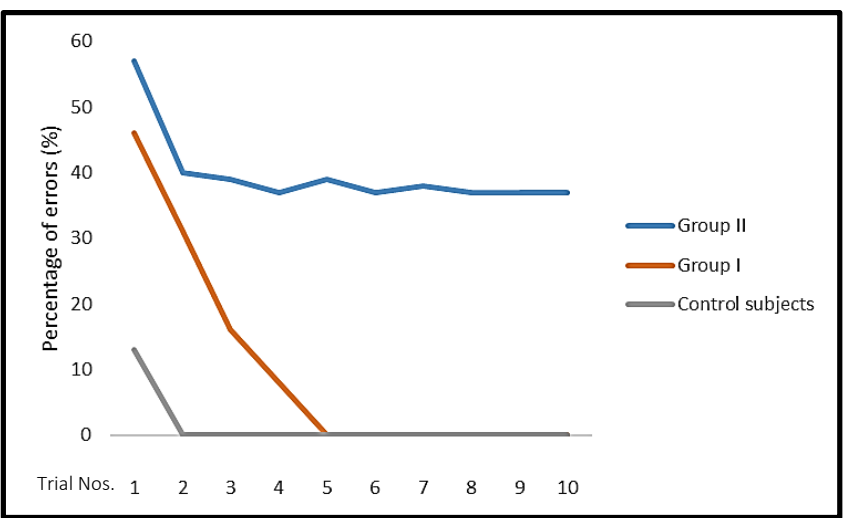

Figure 1. Percentage of subjects' errors based on tests conducted during the arrangement test

9.50, $\mathrm{p}=0.0059$ ). Finally, there is a significant difference between the performance of Group I and Group II patients $(\mathrm{F}(1.46)=10.14, \mathrm{p}=0.0025)$. (Figure 3)

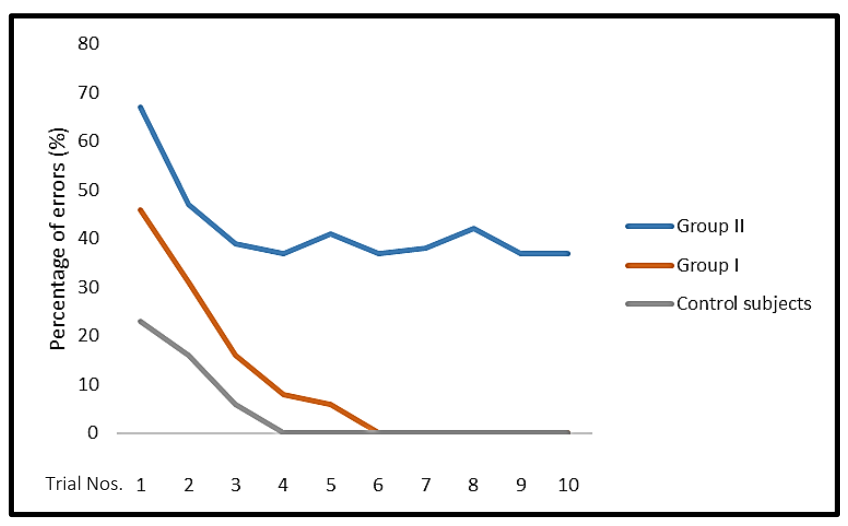

Figure 2. Percentage of subjects' errors based on tests conducted during the designation test

\section{DISCUSSION}

According to the literature, stroke patients face difficulties that often include cognitive impairments, such as memory deficits, attention and language difficulties, and mood disorders such as anxiety and depression (Boakye et al., 2019). ${ }^{4} 45.45 \%$ of our patients had great difficulty in performing a simple test of spatial memory. In fact, patients in group II failed in the various tests of arrangement, designation and evocation of the spatial memory test. They thus presented real disturbances of the memory in the short term. These results confirm the data of Park SH et al., (2017) $)^{5}$ who in a retrospective study from 2014 to 2015 obtained $62 \%$ of patients with memory deficits following a stroke. These

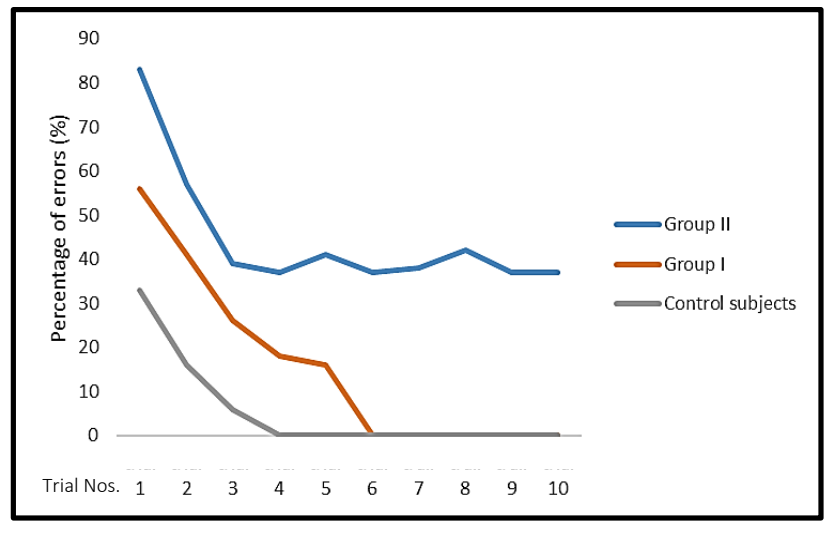

Figure 3. Percentage of subjects' errors based on tests conducted during the evocation test

disturbances in memory are comparable to those obtained by Bakou et al., $(2010)^{6}$ in epileptic patients and Yao et al., $(2011)^{7}$ in subjects three hours after alcoholization with palm wine (koutoukou). Our results are comparable to Zhou et al., $(2016)^{8}$ who obtained stroke and a significant alteration of the spatial memory compared to the witnesses, in the spots of recognition and location of the object in mice. Our results also corroborate previous studies reported by (Karimian et al., 2018 and Oliveira et al., 2001).9,10 The first author observed a significant alteration of visualspatial short-term memory in patients with stroke. The second author noted disturbances in working memory in subjects with stroke in the right hemisphere. Indeed, our tests, in addition to short-term memory, also, of course, test the working memory and its visuospatial register (Adou et al., 1999). ${ }^{11}$ In addition, patients who have successfully learned the spatial arrangement of nine familiar objects $(54.54 \%)$, did so late (group I). This result indicates a transient memory disorder in these patients, as observed (Yao et al., 2011) ${ }^{7}$ in subjects three hours after alcoholization with palm wine (koutoukou) subjected to the same spatial memory test. These different memory disorders could be corrected as a result of adapted rehabilitation programs; or lithuim drug therapy as Sun et al. (2019) ${ }^{12}$ have shown in a population with stroke. On the plan of the mnemic functioning (encoding, storage, recovery), the results would suggest a lack of encoding of the items presented to the patients during the tests.

\section{CONCLUSION}

According to the literature, stroke patients face difficulties that often include cognitive impairments, such as memory deficits. Our study, in addition to confirming this result, indicates that these memory 
disorders manifest themselves to varying degrees. Indeed, the working memory disorders would be more marked in group II patients than in group I patients or they can be considered transient. Difficulties with the encoding of information could explain the slowness of learning observed in these patients. Specific memory disorders (spatial memory, working memory) can occur in patients with stroke. Patients and their parents should be well informed about their existence and the nature of these disorders.

\section{REFERENCES}

1. Olton DS, Becker JT, Handlemann GE. Hippocampus, space and memory. Behavorial and brain sciences 1979; 2:313-65.

2. Tako NA. Modèles expérimentaux des amnésies diencéphaliques d'origine alcoolique et carentielle. Importance des corps mamillaires. Thèse de Doctorat d'état és-Sciences Naturelles. Option neurosciences. Abidjan: Univ. de Cocody- Abidjan. 1995:1. (In French) 3. Fouillot C, Thunnin O. Rapport de stage d'initiation à la recherche au laboratoire de psychologie expérimentale, Université de Nice. 1993:12. (In French) 4. Boakye NT, Scott R, Parsons A, et al. All change: a stroke inpatient service's experience of a new clinical neuropsychology delivery model. BMJ Open Quality 2019;8:eooo184. https://doi.org/10.1136/bmjoq-2017000184

5. Park SH, Sohn MK. The Characteristics of Cognitive Impairment and Their Effects on Functional Outcome After Inpatient Rehabilitation in Subacute Stroke Patients. Ann Rehabil Med. 2017;41(5):734-42.
6. Bakou NF, Camara PA, Yao KM, Adou et B. Assi. Evaluation de la mémoire spatiale chez des patients souffrant d'épilepsie généralisée. Revue médicale de Bruxelles, 2010;31:12-4. (In French)

7. Yao KM, Adou KFJB, Camara PA, Bakou NF, Sert NATB. Effets comparés de l'alcoolisation aiguë au Koutoukou de vin de palme (boisson alcoolique artisanale) et au Pastis 45 (boisson alcoolique industrielle) sur la mémorisation, chez l'homme. Int J Biol Chem Sci. 2011;5(3):1073-81.

8. Zhou LYY, Wright TE. Prefrontal cortex stroke induces delayed impairment in spatial memory. Behav Brain Res. 2016 1;296:373-8.

9. Karimian N, Asgari K, Doost HTN, Oreizi HR, Najafi MR. Investigating patterns of memory impairment in ischemic stroke in an iranian population. Appl Neuropsychol Adult. 2018;25(5):458-63. https://doi.org/10.108o/23279095.2017.1329144

10. Oliveira CR, Pagliarin KC, Calvette LF, Gindri G, Argimon IIL, Fonseca RP. Depressive signs and cognitive performance in patients with a right hemisphere stroke. Codas 2015;27(5):452-7. https://doi.org/10.1590/2317-1782/20152015005.

11. Adou KFJB. Contribution à l'étude de la trypanosomiase humaine africaine (THA) ou maladie du sommeil, en Côte d'Ivoire (approches électrophysiologique comportementale et électroclinique). Thèse de doctorat de zème Cycle en Psychophysiologie, Univ Cocody-Abidjan. 1999;58-73. (In French)

12. Sun YR, Nathan H, Christopher JM. Lithium Carbonate in a Poststroke Population Exploratory Analyses of Neuroanatomical and Cognitive Outcomes. J Clin Psychopharmacol. 2019;39(1):67-71. 